\title{
Inacabamento e cotidiano: um ensaio sobre o contista Marques Rebelo
}

\author{
Open-endedness and daily life: \\ an essay on the short story writer Marques Rebelo
}

\author{
Rafael Souza \\ Colégio Pedro II, Rio de Janeiro / Brasil \\ prof.rafaelima@gmail.com
}

Resumo: Ao longo de sua trajetória como escritor, Marques Rebelo circulou pelos mais variados gêneros literários. A despeito disso, é notável sua inclinação para o conto, com o qual marcou sua estreia no mundo das letras com o volume intitulado Oscarina (1931), seguido por Três caminhos (1933) e Stela me abriu a porta (1942). Mas, mais do que isso: pelo ritmo ágil de suas narrativas e por seus desfechos abertos, é possível identificar o contista Marques Rebelo mesmo em seus romances, especialmente Marafa (1935) e A estrela sobe (1939). Nesse sentido, o presente artigo tem como objetivo analisar a obra rebeliana produzida nesse período levando em consideração, por um lado, certo inacabamento da forma e, por outro, a dimensão da vida cotidiana em suas tramas. Nossa hipótese é a de que, em Rebelo, esses elementos não apenas se correlacionam como concorrem para uma literatura que lhe possibilita: a) escapar ao cânone ensaístico e sociológico - sem necessariamente confrontá-lo; b) criar para si mesmo uma espécie de entrelugar na história da literatura; c) puir qualquer linha hierárquica entre grandes e pequenos dramas humanos no devir histórico.

Palavras-chave: Marques Rebelo; contos; cotidiano. 
Abstract: Throughout his career as a writer, Marques Rebelo wrote works of different literary genres. Nevertheless, his tendency for the short narrative is remarkable and it marked his debut in the world of letters with the book entitled Oscarina (1931), followed by Três caminhos (1933) and Stela me abriu a porta (1942). But more than that: the quick pace of his narratives and their open-endedness allows one to identify the short story writer behind his novels, especially Marafa (1935) and $A$ estrela sobe (1939). In this sense, this article aims to analyze the rebelian works produced during this period as it takes into account, on the one hand, a certain incompleteness of form and, on the other, the significance of everyday life in their plots. Our hypothesis is that, in Rebelo, these elements not only correlate as well as compete for a literature that enables him: a) to avoid the essayistic and sociological canon - without necessarily confronting it; b) to create for himself a kind of in-between space in the history of literature; c) to fray the hierarchical line between large and small human dramas in historical development.

Keywords: Marques Rebelo; short stories; daily life.

Recebido em 22 de maio de 2016.

Aprovado em 25 de julho de 2016.

\section{$1 \mathrm{O}$ conto como (ausência de) destino}

Peço licença ao leitor para iniciar o ensaio com uma citação. É que, na anotação de 13 de março de 1937, Eduardo, alter ego de Marques Rebelo no romance em forma de diário $O$ espelho partido, faz uma queixa sobre o público leitor no Brasil que me parece fundamental e que serve aqui para apresentar a relação entre o autor analisado e o conto como gênero literário em sua época:

- O público brasileiro ainda não acredita no conto, quando é o conto o que a nossa literatura tem, por enquanto, de mais alto. Como não acredita na música de câmara. Ele acha que, em música, a coisa precisa ser orquestral para ser séria. E que, em literatura, a história precisa ter trezentas páginas, no mínimo, para ser profunda (REBELO, 2002b, p. 210). 
Vemos, na defesa do conto enquanto o "mais alto" gênero literário brasileiro, uma das facetas mais interessantes de nosso autor. Rebelo entendia-se como contista, mas, ao mesmo tempo, sabia perfeitamente o quão difícil era sê-lo diante de um público - e também de uma crítica - que, segundo ele, além de parco, não valorizava histórias curtas por considerá-las coisa menor e sem profundidade.

$\mathrm{Na}$ verdade, Rebelo tem pouquíssimas linhas escritas sobre literatura de modo geral e sobre a sua própria em particular. Não sendo autor de temperamento combativo, aos críticos mais ácidos, ou mesmo àqueles que simplesmente o ignoraram, ele não se deu ao trabalho de responder. No limite, é como se ele tivesse adotado como seu o "tédio à controvérsia" machadiano (VENTURA, 1991, p. 103-104). Além disso, seus livros, ao menos as primeiras edições, não contam com qualquer tipo de prefácio ou apresentação que balize, de alguma forma, sua leitura. No máximo encontramos neles epígrafes, mas tão enigmáticas que dificilmente são capazes de induzir o leitor a tomar tal ou qual direção. Sendo assim, menos do que em seus rarefeitos comentários críticos, a tensão experimentada pelo contista junto ao público e ao cânone se expressará de forma visível na própria obra rebeliana, de modo que é possível encontrar o contista em Rebelo mesmo quando estivermos aqui tratando de seus romances. Ou então, o que é um pouco diferente, poderemos observar no conto rebeliano a tentativa natimorta de um romance que foi gradualmente perdendo o fôlego até não poder mais continuar.

Um exemplo do que venho tratando é Três caminhos, o segundo livro de Marques Rebelo, publicado originalmente em 1933. Autobiográfico, o volume é composto por três contos, os quais poderiam ou ter tomado a forma de um único romance ou mesmo formar cada qual um romance autônomo. Essa última possibilidade, aliás, estaria conforme as intenções primeiras do autor, segundo a nota anteposta aos contos: “'Vejo a lua no céu', 'Circo de coelhinhos' e 'Namorada' representam capítulos imperfeitos de três romances tentados, onde cada pequenino herói estava no seu caminho. Se não os prossegui, não foi por negligência ou incapacidade. Falou mais forte a piedade de não lhes dar destinos" (REBELO, 2010b, p. 165).

Exposta em duas frases à primeira vista contraditórias, a advertência é reveladora da tensão experimentada pelo autor. Tensão essa que, de alguma forma, atravessa toda a obra rebeliana. Por um lado, 
Rebelo, cujo primeiro livro também tinha sido um volume de contos, expõe sua frustração por apresentar ao leitor "capítulos imperfeitos de três romances tentados". Ele fala como se tivesse contrariado a expectativa de um público que dele estaria cobrando algum tipo de evolução, representada nesse caso pela passagem de um gênero ao outro, do conto ao romance. Nesse sentido, a frase como que corrobora a queixa e o receio de Eduardo, para quem o conto tendia a ser ignorado pelo leitor brasileiro.

Por ouro lado, na segunda frase, Rebelo parece negar qualquer tentativa frustrada e bancar o resultado final do livro. Assim, ele se justifica ao afirmar que os contos nada têm a ver com negligência ou incapacidade - de escrever romances, esteja visto. Dito de outra maneira: longe de ser um romance em miniatura, o conto, reclama Rebelo, tem a sua especificidade, e essa diz respeito à desobrigação do narrador de dar "destinos" para as suas personagens. É como se o destino de Marques Rebelo fosse escrever contos cujas tramas e personagens fossem sem destino.

Tanto que o que acontece em Três caminhos acontece também com a imensa maioria dos contos rebelianos, ou pelo menos os mais expressivos deles, como Oscarina (1931) ou Stela me abriu a porta (1942), que dão nome aos seus respectivos volumes. Contudo, mesmo em se tratando de seus romances desse mesmo período, como Marafa (1935) e A estrela sobe (1939), podemos observar essa tensão entre um impulso narrativo que resulta tanto em "imperfeição", ou inacabamento, quanto num final em aberto que deixa as personagens sem um destino definido.

Em $A$ estrela sobe, Rebelo nos conta a história de Leniza Mayer, da qual faço aqui um breve resumo: por ter sido criada numa casa de cômodos situada numa estreita e mal iluminada ladeira no já suspeito bairro da Saúde, região central e, à época assim como hoje, decadente do Rio de Janeiro, Leniza conhece desde muito cedo a promiscuidade. É nesse ambiente pobre, de cansaços e desejos recalcados, majoritariamente masculino e dubiamente marginal, que ela aprende a viver utilizandose de sensualidade e erotismo para "subir" na vida sem se dobrar ao papel que lhe seria reservado caso optasse por um casamento no estilo pequeno-burguês, para o qual pretendentes não lhe faltavam, dada a sua atraente e sensual beleza. Em meio a isso, alimenta-se, por seu talento musical, do sonho de se tornar cantora do rádio, do sonho de outra vida, enfim, em que pudesse ser livre das amarras sociais que a prendiam antes mesmo de ela nascer. Em busca desse sonho, Leniza vê-se na condição 
de negar os princípios morais que lhe foram transmitidos por sua mãe e, no limite, abandonar-se a si mesma.

Por mais que o leitor possa deduzir o - triste - fim da história de Leniza antes mesmo da última página, para a sua surpresa Rebelo se recusa a fazê-lo. Prefere deixá-lo em aberto, na forma de pergunta, dando a impressão de que, doravante, não tinha mais condições para acompanhá-la:

[...] aqui termino a história de Leniza. Não a abandonei, mas, como romancista, perdia-a. Fico, porém, quantas vezes, pensando nessa pobre alma tão fraca e miserável quanto a minha. Tremo: que será dela, no inevitável balanço da vida, se não descer do céu uma luz que ilumine o outro lado das suas vaidades? (REBELO, 2010a, p. 222).

Se em Três caminhos uma pequena nota serve de justificativa para o abandono de seus "pequeninos heróis", em A estrela sobe Marques Rebelo o faz apenas nas últimas linhas, (re)assumindo, assim, sua identidade de autor/narrador. Justifica o não final como sendo de sua intenção: "Não a abandonei", diz, mas a "perdi", o que seria diferente.

Já Marafa, vencedor do Grande Prêmio de Romance Machado de Assis, ${ }^{1}$ parece ser composto por dois contos que, correndo em paralelo, só se encontram mediante o acaso provocado pelo próprio autor. De um lado, temos as personagens José e Sussuca e, de outro, Teixerinha e Rizoleta, cada qual vivendo seu drama particular. Comum a ambos os casais, apenas um ambiente no limite do marginal do Rio de Janeiro da década de 1930. Ali, José, funcionário público mediano, se envolve em uma briga com o malandro Teixerinha, que o jura de morte. Teixeirinha, por sua vez, cumpre a promessa e o romance termina, novamente, pela

${ }^{1}$ O prêmio foi criado pela Companhia Editora Nacional, com patrocínio da Associação Brasileira de Imprensa. A comissão julgadora foi composta por Agrippino Grieco, Gastão Cruls, Gilberto Amado, Hebert Moses, Moacyr de Abreu e Monteiro Lobato. Marafa, ou Romance branco (título com o qual o romance foi apresentado ao concurso), dividiu o prêmio com outros três romances "em igualdade de condições quanto ao mérito literário", segundo a ata do júri: Música ao longe, de José Fernando (pseudônimo de Erico Veríssimo), Totônio Pacheco, de Philotecto Telles (pseudônimo de João Alphonsus Guimarães), e Os ratos, de B. Felipe (pseudônimo de Dionélio Machado). Marques Rebelo participou com o pseudônimo de José Maria Nocaute. De cada livro a Companhia Editora Nacional fez uma edição de 2.500 exemplares numerados (cf. REBELO, 1935). 
mais completa arbitrariedade do autor em fazer as duas histórias se encontrarem.

Aqui, mais uma vez Rebelo "perde" suas personagens e, mesmo impondo um trágico final à trama, ele o faz de modo a conseguir o efeito de um não final, até porque as personagens Sussuca e Rizoleta ficam no meio do caminho, sem um "destino" definido. Portanto, há que se buscar as potencialidades do conto rebeliano não propriamente em seus desfechos, mas na singularidade presente no espaço contingencial insinuado por esse livre ato de suspensão na narrativa, onde Rebelo insere sua literatura e a si mesmo, habitando, como disse o poeta Lêdo Ivo (1975, p. 181), uma "zona literária discreta, silente e umbrosa", a qual denomina a "Tijuca da literatura".

Nesse sentido, o inacabamento rebeliano pode revelar traços bastante interessantes, como a economia de expressão - "o que se pode escrever em duas linhas, nunca escrever em três" (REBELO, 2002b, p. 272) - a serviço de uma incrível agilidade narrativa, pela qual, isso é inconteste, Rebelo se destacou entre seus contemporâneos. Nesse ponto, Rebelo desapega-se de tudo aquilo que não lhe parece essencial, agindo como se fosse um caricaturista ou um observador que tudo capta, mas apenas de relance, de passagem. Ao mesmo tempo, o traço apenas esboçado o permite manter uma distância limítrofe em relação a qualquer tipo de investigação ou aprofundamento de caráter psicológico ou social: "Sei da parte de talento que tenho e a que me falta - a densidade, a penetração, a profundeza. Vejo tudo muito de fora. Quem vê de fora não vê nada, ou vislumbra apenas" (REBELO, 2002a, p. 266). Essa também seria a avaliação de Octávio de Faria (1933, p. 285), para quem o "grande conteur" tinha dificuldade em ver além: Rebelo "vê o que está perto - o que todos nós vemos, apenas sem sabermos 'contar' depois - mas deixa ao longe, perdido, velado, todo um mundo que a nós atrai grandemente".

Saber contar aquilo que todo mundo consegue apenas ver. Eis aqui outro elemento próprio dos contos rebelianos. Recordemos, como exemplo, o conto "Em maio". Escrito em primeira pessoa, nele o narrador sai à rua e caminha a esmo numa tarde de domingo: "são os meus passos que me conduzem neste límpido dia de maio [...]" (REBELO, 2010b, p. 65). Assim guiado, enquanto anda, o mundo ao seu redor vai-se nos descortinando gradualmente. Sua presença é discreta, como se um véu o protegesse de quaisquer retribuições e constrangimentos, o que permite a seu olhar repousar onde bem entender. Por estar em movimento, tudo 
é visto de passagem, ou seja, seu olhar não se fixa por muito tempo em nada: passa o bazar, vê a francesinha, atravessa a "rua de maus paralelepípedos por onde passam os bondes barulhentos" (REBELO, 2010b, p. 65), cruza a avenida, passa pela "praça de ardores africanos" (REBELO, 2010b, p. 65), depara-se com um sujeito conhecido, observa a "menina de boina escarlate" (REBELO, 2010b, p. 66) e o guarda-civil a esperar alguém, entra no jardim, etc. Para cada personagem visto em sua cena particular, é feito um breve comentário que vale por si, pois não há quaisquer conectivos entre essas micro-histórias. O fim da tarde marca o fim do olhar e, subsequentemente, do conto, tão sem razão de ser quanto o próprio narrador: "dentro de tanta paz eu sou um homem sem motivo e lá fora, na vida, um tímido que se aterra" (REBELO, 2010b, p. 73).

Sem formar um todo, as imagens se acumulam e estão em correlação com o movimento do narrador que, mais ou menos atento, não se detém por muito tempo em nenhuma delas. A um possível exercício de aprofundamento, Rebelo opõe uma lânguida descrição que impede a formação de qualquer enquadramento ou moldura alienígena à cena. Tudo é visto de passagem, de modo que entre sujeito e objeto reste um espaço estreito que, no entanto, não se deseja transpor. Portanto, não se trata aqui de um "observador de primeira ordem", porque esse espaço não pressupõe uma hierarquia entre o sujeito ativo, dotado da faculdade de conhecer, e o objeto, que assim perderia sua dimensão de coisa. Tampouco a mímesis é colocada em xeque, de modo que sua literatura não pressupõe a presença do "sujeito de segunda ordem", que julga o mundo a partir dos limites de sua própria capacidade de observação (GUMBRECHT, 1998). Em Rebelo, a observância é provisória tão somente porque se submete à fugacidade do movimento: "[...] sou um batedor de imagens, apenas, como os há de carteiras" (REBELO, 2002b, p. 93).

$\mathrm{Na}$ literatura de Marques Rebelo, é comum nos depararmos com cenas como a citada acima, que se desdobram em múltiplas situações e outros tantos personagens (VIDAL, 1997), dando a impressão de ausência de uma trama central em torno da qual girariam todas as outras, ou de um enredo, propriamente (ALMEIDA, 1973), ou ainda de que sua tensão seria mínima (BOSI, 1984). Nesse sentido, na distância que Rebelo mantém entre si mesmo e o outro não há desejo de interpretação, isto é, não se pressupõe um avançar a fronteira, mas apenas um movimentar-se dentro de seus limites. 
Em contrapartida, é sobretudo a partir dessa maneira toda especial de compreender o papel do gênero conto que Rebelo poderá, por um lado, passar ao largo do cânone de seu tempo sem necessariamente confrontá-lo e, por outro, tratar de um de seus temas mais caros, a saber: a dimensão cotidiana e banal da vida de personagens que, na sua ampla maioria, são quase invisíveis de tão pouco importantes do ponto de vista social ou literário.

\section{0 jaquetão sem corte}

De acordo com Cândido (2000), no decênio de 1930 a literatura brasileira destacou-se como um singular instrumento de pesquisa humana e social, o que, somado ao embalo dado pelas transformações no cenário político, a ela conferiria certo caráter de "movimento". Lembremos apenas que, de certa forma, isso se correlaciona ao projeto político-pedagógico varguista, desejoso de promover a formação e divulgação de uma cultura erudita devidamente filtrada com as cores da nacionalidade. Para isso, o Estado contava com a figura do intelectual, convocado a participar diretamente da política como o único capaz de interpretar, dentro da ordem, o conjunto de manifestações representativas da verdadeira cultura nacional (VELLOSO, 2003). Por isso essa geração, composta de figuras como José Lins do Rêgo, Jorge Amado, Raquel de Queiroz e Graciliano Ramos, entre outros, teria podido promover a "incorporação crítica e problematizada da realidade social brasileira" e com isso canonizado o modernismo ao completar a transição do "projeto estético" para o "projeto ideológico" (LAFETÁ, 2000, p. 31).

A esse respeito, é o próprio Marques Rebelo quem fica no meio do caminho, porquanto não é possível inseri-lo naquela tendência sem lançar mão de contorcionismos comprometedores. É que, se não restam dúvidas quanto a sua inspiração popular, por outro lado, não há em Rebelo nenhum esforço efetivo de compreensão do Brasil. Aliás, como se vê pelo desabafo de Eduardo quando do lançamento de Stela me abriu a porta, seu último livro de contos, o próprio Rebelo tinha plena consciência de sua inadequação geracional. Faltava a ele, afinal de contas, o tão reclamado "tempero social" de seu tempo:

A Porta! Outro livro publicado sem a chancela de Vasco Araújo [José Olympio], o que significa não ter o jaquetão cortado pelo alfaiate que dita o sucesso editorial, e sem o 
tempero social que a crítica exige, mais páginas, portanto, para gerar silêncio. E nunca mais escrever contos para evitar o maquinal, que é o despenhadeiro dos escritores (REBELO, 2009, p. 80).

É bem verdade que, em alguns momentos, Rebelo chega às raias da crítica social, como no conto "Onofre, o Terrível, ou A sede de justiça". Onofre é um mata-mosquito, que, por um breve instante, viu-se grande e nobre, um herói mesmo da Saúde Pública, matando, muito mais que larvas, a própria "morte que pairava sobre a cidade. [...] Ele, Onofre Pereira da Silva, o 116 da turma de Botafogo!" (REBELO, 2010b, p. 153). Num ato estranho à grande maioria das personagens rebelianas, Onofre, ao contrastar a importância de seu trabalho com o salário miserável que ganhava em troca, ultrapassa a si mesmo e se revolta contra sua situação de classe, o que notadamente o aproxima das personagens de Lima Barreto, como o major Policarpo Quaresma, que, de acordo com Nicolau Sevcenko (2003), desenvolve uma consciência tal que o permite passar do ufanismo à crítica da dura realidade do país.

Onofre chega, assim, a bolar um plano que, se fosse levado a efeito, o tornaria o redentor de seus coirmãos trabalhadores: e se ele deixasse os mosquitos crescerem e atacarem os ricos, matando-os um por um? Aí, sim, “acabaria a pobreza. Os pobres desceriam da Babilônia, do Pinto, da ladeira do Leme, para invadir as casas. Desceriam como em procissões, vagarosas, quatro a quatro, levando estandartes, imagens de santo, palmas [...]" (REBELO, 2010b, p. 155). Mas, ao fim e ao cabo, falta a Rebelo o impulso crítico e combativo de Lima Barreto, e aqui vemos ressurgir sua singularidade, pois, se Policarpo age e se frustra, Onofre é tão ingênuo que sua ação é suspensa antes mesmo de poder ser colocada em prática. De repente, ele chega à óbvia conclusão de que espécie alguma de mosquito seleciona seus alvos de acordo com a classe social, ou seja, "pobreza não vacina ninguém contra a febre amarela" (REBELO, 2010b, p. 156). O resultado: Onofre conforma-se com a marmita fria, e cabe à brisa do mar apenas o simples trabalho de enxotar "o farrapinho de sonho que teimava" (REBELO, 2010b, p. 158), deixando natimorta sua utópica revolução.

Já "Um destino", título que conforma uma ironia em se tratando da narrativa rebeliana, trata da incômoda herança escravocrata e racial brasileira, mas apenas de forma lateral. O conto narra a história de Antônio, funcionário público preterido por sua noiva em favor de 
Madeira, que também já o havia ofuscado no trabalho simplesmente por ser "doutor" e ele não. Solitário, deixando-se levar pelo acaso da vida, Antônio decide, como compensação, pedir Maria, sua lavadeira, em casamento. Logo em seguida ao aceite, o narrador dá um salto no tempo e é sarcástico ao descrever a vida que levava o novo casal: "Foram morar na casinha do Rio Comprido, muito maltratada pelo último inquilino e que a palmeira, ao lado, diminuía mais. O primeiro, muito clarinho, mas o segundo, o Luís, saíra bem à mãe" (REBELO, 2010b, p. 95). Enquanto isso, Maria, que com tudo se contentava, não percebia a frustração que seu consorte mal conseguia disfarçar por ter contraído matrimônio com uma mulher negra e socialmente inferior, termos equivalentes no conto em questão: "Mas que estúpida! Nem desconfia!... Teve vontade de descompô-la. Teve ânsias de esmurrá-la [...] Penalizou-se: coitada!..." (REBELO, 2010b, p. 96).

O que tenciono dizer é que, por mais que Rebelo se aproxime de temas inegavelmente sensíveis e complexos no tocante à sociedade e à história brasileiras, ao fim e ao cabo ele declina do ensaio sociológico e seus contos acabam por mergulhar em todo um universo humano que não tem a menor consciência das opressões que lhe recai sobre a cabeça. Assim, suas personagens perambulam como Seu João, do conto intitulado "Labirinto", cujas "perturbações" são compartilhadas pelo próprio médico que lhe atende:

[...] Custa um pouco, meu amigo. O senhor durante quatro anos não mudou de lentes. Vai pouco a pouco. Calma. Duram muito essas perturbações. Às vezes vão a meses. São perturbações do labirinto.

Seu João riu amargo:

- Num labirinto vivo eu, doutor!

O médico abaixou os olhos pequenos que (João reparou bem) pareciam ter chorado.

- Também eu, meu amigo, também eu. Todos nós andamos num labirinto (REBELO, 2010b, p. 298-299).

Nem o maior dos esforços de análise de história social poderia revelar um "Marques Rebelo, historiador", na linha em que Chalhoub (2003) interpretou a literatura de Machado de Assis. Isso porque Rebelo suspende aqui e acolá quaisquer ímpetos de investigação sociológica ou de posicionamento ideológico. Afinal de contas, “- Por que pensar que 
escritor social é só aquele que discute salários, que conta as misérias do proletariado?", pergunta-se Eduardo na anotação de 6 de fevereiro de 1942 (REBELO, 2009, p. 43).

Muito embora pertençam a um extrato popular, as personagens rebelianas, sobretudo as de seus contos, habitam um entremeio tão indefinido que, além de não se sentirem impelidas a revoltas ou algum inequívoco impulso de ascensão, não nos permitem depreender contradições ou tensões sociais. Compõem, enfim, um grupo que não se deve confundir com o operariado, classe que, devido ao duplo processo de industrialização e urbanização somado à "ideologia do trabalho" levados a cabo pelo governo Vargas, assumia um inédito protagonismo social no Brasil (GOMES, 1982). E, do mesmo modo, não se adéquam à definição contrária, isto é, à burguesia. Entre esses, Rebelo escolhe permanecer naquela zona umbrosa e eleger como suas as personagens que, à época, o crítico Tristão de Athayde denominou "pequenina burguesia", por não sofrerem o suficiente para querer ascender e nem possuírem o bastante para querer se defender: "O Sr. Marques Rebelo [...] deixou de lado os extremos sociais e ficou nas entre-águas, onde os movimentos são todos amortecidos" (ATHAYDE, 1975, p. 151-152).

\section{Todo dia, tudo sempre igual}

Trocando em miúdos, é a "eterna vidinha das vidinhas" (REBELO, 2002 b, p. 91) que vemos passar pelas páginas rebelianas. É o mundo das crianças em suas brincadeiras pelas ruas suburbanas, dos jovens e humildes casais em busca de meios para contrair matrimônio, das conversas rápidas entreouvidas nos bondes, dos baixos funcionários públicos em seus afazeres burocráticos, do sonhar acordado daqueles que pouco ou nada almejam para si próprios, do viver em pensões, do esperar no ponto do ônibus, dos apertos financeiros, dos sapatos gastos, das donas de casa que contabilizam os mantimentos da casa, das famílias simples à mesa do almoço temperado com pequenas e insignificantes preocupações interiores:

A mosca desapareceu com o safanão higiênico de dona Carlota, que imaginando lá com os seus botões: Aqui há dente de coelho... - não ousava perguntar nada. Olhava para o filho, olhava para o marido... Jorge se achava novamente a cinquenta léguas da vida, seu Santos gostava de goiabada com farinha: 
- Onde está a farinheira?

A mulher saiu correndo, medrosa:

- Já vai - e desculpava-se: - Não é que eu me esqueci!...

Preciso tomar fosfatos. Ando com a cabeça oca (REBELO, 2010b, p. 11),

Rebelo se interessa por revelar tramas cujos contornos, de tão precários, se apagam em pouco tempo. Revelação efêmera de situações também efêmeras, portanto, cuja condição nunca é alterada, como se ele quisesse dar conta do que, por excesso de visibilidade, se torna invisível. Trata-se de um ordinário universo particular com o qual Rebelo demonstra muita intimidade ao mesmo tempo em que evita invadir ou transpor a vida de seus pequenos "pobres-diabos". Disso se depreende que, ao declinar de completar seus movimentos, Rebelo se recusa a lançar mão da escrita, ou melhor, da "hermenêutica do outro" pois a alteridade apreendida por seu olhar passageiro não é tida como desvio nem tampouco como combinação insólita de elementos normativos (CERTEAU, 1982, p. 221). É, nesse sentido, uma literatura "“desintelectualizada", como se tudo o que Rebelo precisasse dizer estivesse apenas nas linhas, e não nas entrelinhas (ATHAYDE, 1975, p. 152).

Voltemos ao já citado conto "Um destino", que narra a história de uma família de subúrbio cujo cotidiano absolutamente comum nos é apresentado a partir do casal Jerome e Dona Veva. Ele é funcionário público de rendimentos medianos, ela, dona de casa. Apesar de alguns percalços corriqueiros, suas vidas seguem sem maiores sobressaltos até que o destino, leia-se a morte, lhes bate à porta. De súbito, sem quaisquer premissas nem explicações, o onisciente narrador rebeliano nos coloca diante do enterro de seu Jerome: "Resmungando, o cocheiro, encartolado, a sobrecasaca coberta de nódoas, fustigou os animais e o enterro partiu, entre o sussurro dos curiosos que se apinhavam no portão da vila, dois automóveis atrás acompanhando" (REBELO, 2010b, p. 62):

- Ele se foi, é o nosso destino, comadre, uma vontade suprema a que nada podemos opor, e como era bom com Deus está. Mas não a deixou sozinha, pense bem. E os filhinhos? E...

Dona Veva espantou os olhos gastos para seu Azevedo, que emudeceu, e, quando pensou nos seus cinco filhos, aí é que ela viu mesmo que estava sozinha e de mãos para o céu começou a gritar (REBELO, 2010b, p. 64). 
No limite, é como se simplesmente não houvesse saída possível, ainda que virtual, para os "labirintos" particulares das personagens rebelianas, mas apenas ranhuras no ramerrão de todo dia, sob o qual estão irremediavelmente submetidos os seus dramas.

A rotina e a intimidade do lar, aliás, figuram entre os temas rebelianos mais recorrentes, em que personagens são amiúde apresentados em seus hábitos absolutamente alheios a qualquer tipo de cálculo, e que não chegam a ter força suficiente para representar relações de causa e efeito em suas histórias:

O jantar é a única refeição que todos fazem juntos durante a semana e durante o qual os filhos são repreendidos de várias maneiras e por variadíssimas causas. Mas, como a fome é conciliadora, tudo acaba muito bem às sete horas para seu Alfredo, que vai tirar a tora na varanda, na cadeira de balanço, e para os garotos, que voltam para o seu verdadeiro domicílio - a rua. Para dona Consuelo, não. Tem que tratar ainda da cozinha, lavar os pratos, guardar a louça, arear as panelas... O rádio está ligado na Estação do Povo - sambas, marchinhas, coisa decente, piadas de matuto, português, turco e italiano. Dona Consuelo chega a parar os seus afazeres para apreciar e rir. De vez em quando dá um palpite:

- Boa, hem?

Seu Alfredo é mais refinado:

-Assim, assim (REBELO, 2004, p. 69-70).

O narrador, que observa a cena como se membro da família fosse, dada a intimidade com que dela se inteira, parece não ser guiado por outro objetivo que não o de anotar a maneira como vivem aqueles pequenos seres que não podem suscitar no leitor nenhuma expectativa de arrebatamento. Somadas e perfiladas, essas historietas formam no horizonte uma oblíqua coesão, posto que não possuem ponto de chegada ou plano de fuga. E nisso levam a inconfundível marca do sempre irônico Rebelo, pois, "tal qual os zebus da mesma manada, ajusta[m]-se à fieira dos anteriores com a uniformidade dos pés duma lacraia, o que não deixa de ser um mérito literário - a unidade!" (REBELO, 2002b, p. 91).

Em outras palavras, a própria noção de obra é paradoxal para o conjunto da ficção de Marques Rebelo, na qual a pasmaceira, ela mesma, engastada num presente tão amplo quanto arrastado, independente do 
passado e desatrelada do futuro, ganha autonomia em relação aos atos das personagens e chega ao paroxismo de assumir o papel principal. Conjugando proximidade e distância, a narrativa rebeliana presta-se, portanto, a dar cabo dum vazio, ou melhor, molda a ausência de fatos e, consequentemente, da temporalidade daquelas vidas-coisa. Sob essa perspectiva, Rebelo age como que animado pelo mesmo espírito que anima o cronista, isto é, sua literatura se aproxima da crônica nos termos definidos por Machado de Assis, para quem esse gênero "fareja todas as coisas miúdas e grandes, e põe tudo em pratos limpos" (ASSIS, $1896^{2}$ apud NEVES, 1995, p. 21).

E, com efeito, Rebelo experimenta um período da história no qual a fronteira entre as "coisas miúdas e grandes" se torna turva, porquanto essas afetam aquelas e nelas se fazem sentir de maneira vertiginosa. Seja como for, a impressão que temos é a de que o autor se furta deliberadamente de estabelecer qualquer tipo de hierarquia entre o graúdo e o miúdo dos eventos. Porém, mais do que isso: ele faz questão de não suprimir a particularidade da experiência cotidiana em favor da história factual. Age, assim, como Eduardo, que, em meio às tensões provocadas mundo afora pela Segunda Guerra, é sensível o suficiente para poder respeitar o íntimo e precário espaço onde se desenrolam as mínimas e mesmo as mais desimportantes contingências de seu interesse pessoal e familiar:

Dois ultimatos: o da Liga das Nações ao governo russo, a propósito da Finlândia, e o de Vera e Lúcio a Papai Noel, exigindo bonecas, carrinho de boneca, mobílias, aparelhinhos de louças, panelinhas, automóveis de corrida e ameaçadoras bolas, que não sei se serão concedidas, dado que apartamento não é campo de futebol (REBELO, 2002a, p. 168).

É certo que para ele "o mundo tornou-se menor. Um gemido londrino é ouvido no Brasil, uma ferida no peito maquis faz escorrer sangue em rua carioca" (REBELO, 2002a, p. 306), e mesmo assim esses dois domínios, o do "mundo" e o da "rua" ou da casa, embora concomitantes, sustentam cada qual sua própria dinâmica, o que possibilita a esse último uma preciosa autonomia apesar da interferência exercida pelo primeiro

\footnotetext{
${ }^{2}$ ASSIS, Machado de. A=B. Gazeta de Notícias, Rio de Janeiro, 16 set.1896.
} 
sobre ele. Daí também a frequente - mas apenas aparente - tranquilidade que atravessa a vida de muitas de suas personagens, manejada com sarcasmo e ternura tão finos quanto indisfarçáveis.

\section{Conclusão}

Com este breve ensaio, busquei demonstrar que a inclinação de Marques Rebelo para o conto possui uma íntima relação com a sua concepção da vida cotidiana. Se, em linhas gerais, convenço o leitor, encerro reafirmando que, em seu conjunto, a literatura rebeliana pode ser vista então como aquilo que Margarida de Souza Neves (1995, p. 25) chamou de "cotidiano monumentalizado", cuja validade é por Rebelo posta à prova, a todo momento, ao relento do tempo. Paradoxalmente, no entanto, o material do qual Rebelo se utiliza é frágil demais para durar, o que demonstra um suposto dar de ombros para a permanência na memória, ou seja, para deixar um legado ou uma marca de distinção na história da literatura: "-Consola-me o pressentimento de que o mundo não precisará mais de obras-primas” (TRIGO, 1996, p. 97).

Sendo assim, entendo também que essa interpretação pode abrir caminho para se rever uma das avaliações mais recorrentes em relação a Rebelo, a saber: a de que se trata de um autor que, apesar da sua relevância, ainda resta esquecido pela crítica e, sobretudo, pelo público geral. Há que se reconhecer que, muito mais que aos críticos e leitores, cabe ao próprio Rebelo o papel de protagonista de seu próprio esquecimento. Em outras palavras: nosso autor concorreu, ele mesmo, para construir para si a memória de um escritor pouco lembrado. Isso pode ser pensado não apenas através da imagem que ele buscou constituir junto à figura de Manuel Antônio de Almeida, autor de Memórias de um sargento de milícias e que durante muito tempo restou igualmente esquecido, mas também pelo próprio material e tratamento dado na narrativa rebeliana à vida cotidiana. 


\section{Referências}

ALMEIDA, Paulo Mendes de. ... Quando viu em Marques Rebelo o criador do moderno conto nacional. In: REBELO, Marques. Oscarina. São Paulo: Clube do Livro, 1973. p. 3-5.

ATHAYDE, Tristão de. [Marques Rebelo e o Modernismo]. Revista Brasileira de Letras, Rio de Janeiro, Academia Brasileira de Letras, fase IV, ano I, n. 1, p. 148-155, out.-dez. 1975.

BOSI, Alfredo. História concisa da literatura brasileira. São Paulo: Cultrix, 1984.

CÂNDIDO, Antônio. Literatura e sociedade. 8. ed. São Paulo: T. A. Queiroz, Publifolha, 2000.

CERTEAU, Michel de. A escrita da história. Rio de Janeiro: Forense Universitária, 1982.

CHALHOUB, Sidney. Machado de Assis, historiador. São Paulo: Companhia das Letras, 2003.

FARIA, Octávio de. Três caminhos. Boletim de Ariel, Rio de Janeiro, ano II, n. 11, p. 285, 1933.

GOMES, Angela Maria de Castro. A construção do homem novo: o trabalhador brasileiro. In: OLIVEIRA, Lúcia Lippi; VELLOSO, Mônica Pimenta; GOMES, Angela Maria de Castro. Estado Novo: ideologia e poder. Rio de Janeiro: Zahar Ed., 1982. p. 151-166.

GUMBRECHT, Hans Ulrich. Cascatas da modernidade. In: Modernização dos sentidos. São Paulo: Ed. 34, 1998. p. 9-32.

IVO, Lêdo. [Análise de O trapicheiro, de Marques Rebelo]. Revista Brasileira de Letras, Rio de Janeiro, Academia Brasileira de Letras, fase IV, ano I, n. 1, p. 180-183, out.-dez. 1975.

LAFETÁ, João Luiz. 1930: a crítica e o modernismo. São Paulo: Duas Cidades, Ed. 34, 2000.

NEVES, Margarida de Souza. História da crônica. Crônica da história. In: RESENDE, Beatriz (Org.). Cronistas do Rio. Rio de Janeiro: José Olympio, CCBB, 1995. p. 15-31. 
REBELO, Marques. A estrela sobe. 4. ed. Rio de Janeiro: José Olympio, 2010a.

REBELO, Marques. A guerra está em nós. Rio de Janeiro: José Olympio, 2009.

REBELO, Marques. A mudança. Rio de Janeiro: Nova Fronteira, 2002a.

REBELO, Marques. Contos reunidos. 3. ed. Rio de Janeiro: José Olympio, 2010b.

REBELO, Marques. Marafa. Rio de Janeiro: Nova Fronteira, 2003a.

REBELO, Marques. Marafa. São Paulo: Companhia Editora Nacional, 1935.

REBELO, Marques. Melhores crônicas. Seleção e prefácio de Renato Cordeiro Gomes. São Paulo: Global, 2004.

REBELO, Marques. O simples coronel Madureira. 3. ed. Rio de Janeiro: Nova Fronteira, 2.

REBELO, Marques. O trapicheiro. Rio de Janeiro: Nova Fronteira, 2002b.

SEVCENKO, Nicolau. Literatura como missão: tensões sociais e criação cultural na Primeira República. 2. ed. São Paulo: Companhia das Letras, 2003.

TRIGO, Luciano. Marques Rebelo: mosaico de um escritor. Rio de Janeiro: Relumpé-Damará, Rioarte, 1996.

VELLOSO, Mônica Pimenta. Os intelectuais e a política cultural do Estado Novo. In: DELGADO, Lucília de Almeida Neves; FERREIRA, Jorge (Org.). O Brasil republicano: o tempo do nacional-estatismo. Rio de Janeiro: Civilização Brasileira, 2003. p. 145-179.

VENTURA, Roberto. Estilo tropical: história cultural e polêmicas literárias no Brasil, 1870-1914. São Paulo: Companhia das Letras, 1991.

VIDAL, José Ariovaldo. A fiç̧ão inacabada: uma leitura de Marques Rebelo. 1997. 201 f. Tese (Doutorado em Teoria Literária e Literatura Comparada) - Faculdade de Filosofia, Letras e Ciências Humanas, Universidade de São Paulo, São Paulo, 1997. 